\title{
Nitric oxide and platelet energy metabolism
}

\author{
Marian Tomasiak $^{1 凶}$, Halina Stelmach ${ }^{1}$, Tomasz Rusak ${ }^{1}$ and Jolanta Wysocka ${ }^{2}$ \\ ${ }^{1}$ Department of Physical Chemistry and ${ }^{2}$ Department of Pediatric Laboratory Diagnostics, \\ Medical University of Biatystok, Biatystok, Poland
}

Received: 13 November, 2003; revised: 22 March, 2004; accepted: 05 April, 2004

Key words: glycolysis, mitochondrial energy production, nitric oxide, porcine platelets

This study was undertaken to determine whether nitric oxide (NO) can affect platelet responses through the inhibition of energy production. It was found that NO donors: $S$-nitroso- $N$-acetylpenicyllamine, SNAP, $(5-50 \mu \mathrm{M})$ and sodium nitroprusside, SNP, (5-100 $\mu \mathrm{M})$ inhibited collagen- and ADP-induced aggregation of porcine platelets. The corresponding $\mathrm{IC}_{50}$ values for SNAP and SNP varied from 5 to 30 $\mu \mathrm{M}$ and from 9 to $75 \mu \mathrm{M}$, respectively. Collagen- and thrombin-induced platelet secretion was inhibited by SNAP $\left(\mathrm{IC}_{50}=50 \mu \mathrm{M}\right)$ and by SNP $\left(\mathrm{IC}_{50}=100 \mu \mathrm{M}\right)$. SNAP (20-100 $\mu \mathrm{M})$, SNP $(10-200 \mu \mathrm{M})$ and collagen $(20 \mu \mathrm{g} / \mathrm{ml})$ stimulated glycolysis in intact platelets. The degree of glycolysis stimulation exerted by NO donors was similar to that produced by respiratory chain inhibitors (cyanide and antimycin A) or uncouplers (2,4-dinitrophenol). Neither the NO donors nor the respiratory chain blockers affected glycolysis in platelet homogenate. SNAP (20-100 $\mu \mathrm{M})$ and SNP (50-200 $\mu \mathrm{M}$ ) inhibited oxygen consumption by platelets. The effect of SNP and SNAP on glycolysis and respiration was not reduced by $1 \mathrm{H}-[1,2,4]$ oxadiazolo-[4,3-a]quinoxalin-1-one, a selective inhibitor of NO-stimulated guanylate cyclase. SNAP (5-100 $\mu \mathrm{M})$ and SNP (10-300 $\mu \mathrm{M})$ inhibited the activity of platelet cytochrome oxidase and had no effect on NADH: ubiquinone oxidoreductase and succinate dehydrogenase. Blocking of the mitochondrial energy production by antimycin A slightly affected collagen-evoked aggregation and strongly inhibited platelet secretion. The results indicate that: 1 ) in porcine platelets NO is able to diminish mitochondrial energy production through the inhibition of cytochrome oxidase, 2) the inhibitory effect of NO on platelet secretion (but not aggregation) can be attributed to the reduction of mitochondrial energy production.

\footnotetext{
${ }^{凶}$ Corresponding author: Marian Tomasiak, Department of Physical Chemistry, Medical University of Białystok, J. Kilinskiego 1, 15-089 Białystok, Poland; phone: (48 85) 748 5710; fax: (48 85) 748 5416; e-mail: mtomask@amb.edu.pl

Abbreviations: NO, nitric oxide; ODQ, 1H-[1,2,4] oxadiazolo-[4,3-a]quinoxalin-1-one; PPP, platelet poor plasma; PRP, platelet rich plasma; SNAP, $S$-nitroso- $N$-acetylpenicyllamine; SNP, sodium nitroprusside.
} 
Nitric oxide (NO) has been increasingly recognized as an important intra- and intercellular messenger molecule with a physiological role in vascular relaxation, platelet physiology, neurotransmission and immune responses (Moncada et al., 1991; Radomski et al., 1996; Szabó, 1996; Riedel et al., 1999; Titheradge 1999). In vitro NO is a strong inhibitor of platelet adhesion and aggregation (Radomski et al., 1996; Riedel et al., 1999; Sogo et al., 2000). In the blood stream, platelets remain in contact with NO that is permanently released from the endothelial cells and from activated macrophages (Moncada et al., 1991; Riedel et al., 1999; Titheradge 1999). It has been suggested that the activated platelet itself is able to produce NO (Lantoine et al., 1995; Zhou et al., 1995; Radomski et al., 1996). The mechanism responsible for the inhibitory effect of NO on platelet responses is not entirely clear. It is believed that the main intracellular target for NO in platelets is soluble cytosolic guanylate cyclase (Waldman \& Walter 1989; Schmidt et al., 1993; Wang et al., 1998). NO activates the enzyme (Schmidt et al., 1993). Thus, elevated intracellular cGMP level inhibits platelet activation. There are suggestions, however, that elevated cGMP may not be the only intracellular factor directly involved in the inhibition of platelet activation (Gordge et al., 1998; Sogo et al., 2000; Beghetti et al., 2003).

Studies performed in the last several years have shown that NO is able to inhibit mitochondrial respiration (Brown, 1999). It is now well documented that, at least in vitro, low (nanomolar) concentrations of NO specifically inhibit cytochrome oxidase (cytochrome $a a_{3}$, complex IV) in competition with oxygen (Brown, 2001). Higher concentrations of NO are able to inhibit other respiratory chain complexes (complex I, II and III) probably by nitrosylating or oxidizing protein thiols and removing iron from the iron sulfur centers (Brown, 1999). Moreover, it has been reported that NO can affect a tricarboxylic acid cycle enzyme, aconitase. Interestingly, the sensitivity of isolated guanylate cyclase to NO is similar to that of cytochrome oxidase (Stone \& Marletta, 1996; Brown 2001). It is therefore possible that also in platelets NO can affect their responses through the inhibition of mitochondrial energy production. To our knowledge the effect of NO on platelet energy metabolism has never been studied before.

The present study is the first to compare the effects of NO donors on the platelet energy metabolism and on their aggregation and secretion. It was found that in porcine platelets NO donors at concentrations similar to that affecting platelet secretion reduced mitochondrial energy production through the inhibition of cytochrome oxidase. It is therefore possible that NO may affect platelet secretion through the inhibition of mitochondrial energy production.

\section{MATERIALS AND METHODS}

Chemicals. Imipramine, antimycin A, rotenone, Hepes, EGTA, dimethyl sulfoxide ( $\mathrm{Me}_{2} \mathrm{SO}$ ), apyrase, cytochrome $c$ type III, 2,6-dichlorophenolindophenol (DCIP), phenazine methosulfate (PMA), fatty acid free bovine serum albumin, sodium succinate, 2,4-dinitrophenol (DNP) $S$-nitroso- $N$-acetylpenicyllamine (SNAP), sodium nitroprusside (SNP), 1H-[1,2,4] oxadiazolo-[4,3-a]quinoxalin-1-one (ODQ), decylubiquinone (DBQ) and soybean trypsin inhibitor were purchased from Sigma Chem. Com. (St. Louis, MO, U.S.A.). Collagen was from Hormonchemie (Munich, Germany). Thrombin (human) was from La Roche (Basel, Switzerland). 5-Hydroxy $\left[\gamma_{-}{ }^{3} \mathrm{H}\right]$ tryptamine creatinine sulfate $\left(\left[{ }^{3} \mathrm{H}\right] 5-\mathrm{HT}\right)$ with a specific activity of 8.6 $\mathrm{Ci} / \mathrm{mmol}$ was purchased from the Radiochemical Center (Amersham, England). Other reagents were analytical grade products. Rotenone and DBQ were dissolved in $\mathrm{Me}_{2} \mathrm{SO}$. ODQ was initially prepared as stock solution $(10 \mathrm{mM})$ in $\mathrm{Me}_{2} \mathrm{SO}$ and stored in 
aliquots at $-20^{\circ} \mathrm{C}$. On the day of use this compound was further diluted with deionized water.

Decomposition of SNP and SNAP. Decomposed SNP (Yamamoto \& Bing, 2000) and SNAP (Singh et al., 1996) were obtained by allowing the NO donors to decay in $0.1 \mathrm{M}$ Tris,

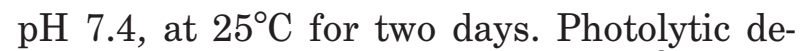
composition was performed in $3 \mathrm{~cm}^{3}$ quartz cuvettes. Samples were irradiated while stirring with light from a deuterium lamp.

Blood collection. Blood was collected in the local slaughterhouse from adult pigs. The blood was withdrawn by direct carotid catheterization and collected into $3.8 \%(\mathrm{w} / \mathrm{v})$ sodium citrate, one volume per nine volumes of blood.

Preparation of platelet-rich plasma (PRP) and platelet-poor plasma (PPP). Platelet-rich plasma was obtained by centrifugation of the blood at $200 \times \boldsymbol{g}$ for 20 min at room temperature. Platelet-poor plasma was obtained by further centrifugation of PRP at $2700 \times \boldsymbol{g}$ for $10 \mathrm{~min}$.

Preparation of platelet concentrate. Blood collected into ACD (0.075 M citric acid, $0.085 \mathrm{M}$ sodium citrate and $0.11 \mathrm{M}$ glucose) solution (one volume per six volumes of blood) was centrifuged at $200 \times \boldsymbol{g}$ for $15 \mathrm{~min}$ and the resulting supernatant was centrifuged again to obtain platelet-rich plasma. The latter was further centrifuged at $1200 \times$ $\boldsymbol{g}$ for $15 \mathrm{~min}$. The resulting platelet pellet was resuspended in a small volume of the plasma and centrifuged at $250 \times \mathbf{g}$ for $10 \mathrm{~min}$. This step was repeated if necessary until contaminating erythrocytes and leucocytes were removed (less than one cell per 5000 platelets). The platelets were collected by centrifugation at $1000 \times \boldsymbol{g}$ for $15 \mathrm{~min}$. Since the energy metabolism of platelets is affected by artificial media (Nishimura \& Minakami, 1975), dialyzed plasma was used as the suspending medium. Platelets were washed twice with dialyzed plasma by centrifugation at $1000 \times \boldsymbol{g}$ for $15 \mathrm{~min}$. The final platelet pellet, obtained from $2 \mathrm{l}$ of blood, was suspended in $20 \mathrm{ml}$ of dialyzed plasma and is referred to as the platelet concentrate. All procedures were carried out at room temperature with plastic vessels and pipettes. If necessary, $\mathrm{pH}$ of the concentrate was adjusted by the addition of $0.2 \mathrm{M}$ $\mathrm{NaOH}$ or $0.2 \mathrm{M} \mathrm{HCl}$ to the stirred suspension.

For some experiments (determination of enzyme activities), the platelets were washed twice and finally suspended in a medium consisting of $0.155 \mathrm{M} \mathrm{NaCl}, 5 \mathrm{mM}$ EDTA and 10 $\mathrm{mM}$ Hepes buffer ( $\mathrm{pH}$ 7.4), referred to as the $\mathrm{NaCl}$ medium.

Plasma was dialyzed as described by Nishimura \& Minakami (1975) against $145 \mathrm{mM} \mathrm{NaCl}, 5 \mathrm{mM} \mathrm{KCl}, 1 \mathrm{mM} \mathrm{MgCl} 2,5 \mathrm{mM}$ sodium phosphate buffer, and $10 \mathrm{mM}$ Hepes buffer, $\mathrm{pH} 7.4$, for $30 \mathrm{~h}$ at $4^{\circ} \mathrm{C}$ and stored in small portions at $-70^{\circ} \mathrm{C}$. The osmolality of all media was adjusted to $340 \mathrm{mOsm} / \mathrm{kg}$ with the major salt.

Platelets were counted using a phase contrast microscope.

Preparation of platelet homogenates. Platelet concentrate obtained from 21 of fresh blood was suspended in $2 \mathrm{ml}$ of a medium consisting of $0.155 \mathrm{M} \mathrm{NaCl}, 5 \mathrm{mM}$ EDTA, $0.5 \%(\mathrm{w} / \mathrm{v})$ fatty acid free bovine serum albumin, $0.25 \mathrm{mg} / \mathrm{ml}$ soybean trypsin inhibitor and $10 \mathrm{mM}$ Hepes buffer (pH 7.4). The suspension was cooled and sonically disrupted (4 bursts, each at $20 \mathrm{kHz}$ for $15 \mathrm{~s}$ at $0^{\circ} \mathrm{C}$ with $30 \mathrm{~s}$ intervals between the bursts). Immediately after sonication the samples were used for estimation of cytochrome oxidase and succinate dehydrogenase activities.

Assay of platelet aggregation. Platelet aggregation was followed turbidimetrically by recording the light transmission through a stirred platelet suspension in the plastic cuvette of an aggregometer (Elvi, Logos, Milan, Italy) at $37^{\circ} \mathrm{C}$ (Born, 1963). Samples of PRP (300 $\mu \mathrm{l})$ were incubated with stirring for $2 \mathrm{~min}$ at $37^{\circ} \mathrm{C}$. Then the threshold concentrations of the stimulus were added to induce the aggregation. For each platelet preparation, the threshold aggregating concentrations, de- 
fined as the minimum amount of the stimulus that induced an at least $70 \%$ increase in light transmission within 3 min was selected. The tested substances were added to the platelet suspension two minutes prior to the addition of the stimulator. The aggregometer was adjusted before each test so that in each platelet preparation the value for light transmission for PRP was $0 \%$ and that for PPP was $100 \%$. Aggregation was quantified by measuring the peak increase in light transmission (extent of platelet aggregation) after adding the respective agonist. All experiments were performed at least in quadruplicate using 4-5 different platelet preparations.

Measurement of platelet secretion. Secretion was determined by the release of ${ }^{3} \mathrm{H}$-serotonin essentially as described by Holmsen \& Dangelmaier (1989). To load platelets with serotonin freshly prepared PRP was incubated with $\left[{ }^{3} \mathrm{H}\right] 5-\mathrm{HT}(1 \mu \mathrm{Ci} / \mathrm{ml})$ for $45 \mathrm{~min}$ at $37^{\circ} \mathrm{C}$. At these experimental conditions more than $92 \%$ of the ${ }^{3} \mathrm{H}$-serotonin added entered the cells. After acidification to $\mathrm{pH} 6.5$ of the PRP with $1 \mathrm{M}$ citric acid, the suspension was centrifuged at $1500 \times \mathbf{g}$ for 20 min to obtain a pellet which was resuspended in a $\mathrm{Ca}^{2+}$-free Tyrode-Hepes buffer containing: $139 \mathrm{mM} \mathrm{NaCl}, 2.8 \mathrm{mM} \mathrm{KCl}$, $8.9 \mathrm{mM} \mathrm{NaHCO} 3,0.8 \mathrm{mM} \mathrm{KH}_{2} \mathrm{PO}_{4}, 0.8 \mathrm{mM}$ $\mathrm{MgCl}_{2}, 5.6 \mathrm{mM}$ glucose, $10 \mu \mathrm{M}$ EGTA, $10 \mathrm{mM}$ Hepes, pH 7.4 , albumin $(3.5 \mathrm{mg} / \mathrm{ml})$ and apyrase $(2 \mathrm{U} / \mathrm{ml})$. The platelets were washed once and suspended in the same buffer without apyrase and EGTA. Imipramine was added to the solution at $1 \mathrm{mM}$ in order to prevent re-uptake of secreted $\left[{ }^{3} \mathrm{H}\right] 5-\mathrm{HT}$. Secretion was estimated at $37^{\circ} \mathrm{C}$ in stirred $(800$ RPM) $1 \mathrm{ml}$ aliquots of $\left[{ }^{3} \mathrm{H}\right] 5$-HT-loaded platelets by the addition of threshold concentrations of thrombin (usually about $0.3 \mathrm{U} / \mathrm{ml}$ ). Prior to the addition of the stimulus the platelets were preincubated for 2 min with $\mathrm{NO}$ donors. Aliquots of $0.2 \mathrm{ml}$ were taken from the incubation mixture at time 0 and $4 \mathrm{~min}$ and put to $80 \mu \mathrm{l}$ of ice cold stop solution containing $3 \mathrm{mM}$ EDTA and $1.5 \%(\mathrm{w} / \mathrm{v})$ formalde- hyde. The aliquots were immediately mixed and centrifuged at $11000 \times \mathbf{g}$ for $1.5 \mathrm{~min}$. $\left[{ }^{3} \mathrm{H}\right] 5$-HT released from the platelets was determined by counting the supernatant in a liquid scintillation counter using Instagel (Canberra, Packard) (5 ml) as a scintillant.

Simultaneous measurement of platelet aggregation and secretion. The platelet release reaction was monitored simultaneously with optical aggregation. The release of dense granule ATP from aggregating platelets was detected in lumiaggregometer (Chrono-Log Corp., Havertown, PA, U.S.A.) as light emission produced by the reaction of ATP with luciferin catalyzed by luciferase (Chronolume). The aggregation and secretion tracings were plotted on a dual channel recorder as a change in optical transmission. All procedures were conducted in accordance with the Chrono-Log Diagnostic Protocol (1987). Samples of PRP (0.45 ml) were incubated with 50 $\mu \mathrm{l}$ of Chrono-lume (luciferin/luciferase reagent) in the cuvette of an aggregometer at $37^{\circ} \mathrm{C}$ for $30 \mathrm{~s}$ with stirring (1000 r.p.m.). After incubation collagen $(20 \mu \mathrm{g} / \mathrm{ml})$ was added, and the aggregation and ATP secretion tracings were recorded for $3 \mathrm{~min}$.

Measurement of glycolysis in intact platelets. Platelets $\left(2 \times 10^{9}\right.$ platelets $\left./ \mathrm{ml}\right)$ suspended in dialyzed plasma were incubated at $37^{\circ} \mathrm{C}$ in a plastic vessels $(50 \mathrm{ml}$ conical Falcon tubes) with gentle stirring under the atmosphere of $95 \% \mathrm{O}_{2}+5 \% \mathrm{CO}_{2}$. Every $5 \mathrm{~min}$ the $\mathrm{pH}$ of the incubation mixture was checked and, if necessary, corrected by the addition of $0.2 \mathrm{M} \mathrm{NaOH}$ (total volume of added $\mathrm{NaOH}$ never exceeded $5 \%$ of the volume of platelet suspension). Incubation was started by the addition of glucose to a final concentration of $10 \mathrm{mM}$ and was carried out for $30 \mathrm{~min}$. It was stopped by the addition of 3 volumes of cold $6 \%(\mathrm{w} / \mathrm{v})$ perchloric acid. Lactate was measured enzymatically in the deproteinized and neutralized extract (Gutmann \& Wahlefeld, 1985). The formation of lactate was found to be linear through the $30 \mathrm{~min}$ incubation. 
Measurement of glycolysis in cell-free system. Platelets obtained from 21 of blood were suspended in $20 \mathrm{ml}$ of dialyzed plasma. The concentrate was cooled to $0^{\circ} \mathrm{C}$, supplemented with dithiothreitol (1.5 mM final concentration) and sonically disrupted. Immediately after sonication samples were taken for the measurement of glycolytic activity. To 1 $\mathrm{ml}$ of glycolytic medium containing all coenzymes and cofactors 1-50 $\mu \mathrm{l}$ of the tested substance was added, the volume was adjusted to $1.1 \mathrm{ml}$ with $0.154 \mathrm{M} \mathrm{KCl}$ and kept for $3 \mathrm{~min}$ at $37^{\circ} \mathrm{C}$. Incubation was started by the addition of $0.4 \mathrm{ml}$ of platelet homogenate. The incubation cocktail contained in the final volume of $1.5 \mathrm{ml}: 45 \mathrm{mM} \mathrm{KCl}, 37 \mathrm{mM} \mathrm{NaCl}, 5$

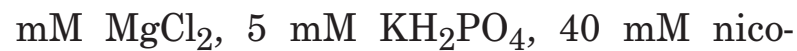
tinamide, $10 \mathrm{mM}$ glucose, $1 \mathrm{mM}$ ATP, $0.5 \mathrm{mM}$ $\mathrm{NAD}^{+}$and $50 \mathrm{mM}$ Hepes-K buffer, $\mathrm{pH}$ 7.4. Incubation was carried out at $37^{\circ} \mathrm{C}$ for $30 \mathrm{~min}$. It was stopped by the addition of $3 \mathrm{ml}$ of cold $6 \%(\mathrm{w} / \mathrm{v})$ perchloric acid. In the control sample (time $=0$ ) perchloric acid was added before the homogenate. Lactate was measured enzymatically in deproteinized and neutralized extract (Gutman \& Wahlefeld, 1985).

Measurement of the respiration rate. Respiration was measured polarographically with a Clark-type oxygen electrode (Yellow Springs, U.S.A.), model YSI 4004, in a closed plastic vessel of $2 \mathrm{ml}$ at $37^{\circ} \mathrm{C}$. Platelet concentrate (suspension in dialyzed plasma), $1 \mathrm{ml}$ and $1 \mathrm{ml}$ of dialyzed plasma were added to the vessel to give the final platelet concentration of $3 \times 10^{9}$ cells $/ \mathrm{ml}$. Measurements were started after 2 min preincubation and were carried out for $10 \mathrm{~min}$. Additions to the measuring system were done 3 min after starting the recording of oxygen consumption. No exogenous glucose was added.

Assay of succinate dehydrogenase activity. The activity of succinate dehydrogenase (EC 1.3.99.1) was measured as described by King (1967). The principle of the assay is based on the reduction of phenazine methosulfate (PMS) by succinate and its dehydrogenase. Reduced PMS is immediately reoxidized by 2,6-dichlorophenolindophenol (DCIP); bleaching of the latter dye is estimated spectrophotometrically. A series of four disposable spectrophotometer cuvettes were prepared to permit varying the PMS concentration and thus determination of $V_{\max }$ (PMS). Each cuvette contained: $0.5 \mathrm{ml}$ of $0.3 \mathrm{M}$ phosphate buffer (K), pH 7.4, $0.3 \mathrm{ml}$ $0.2 \mathrm{M}$ sodium succinate, $100 \mu \mathrm{l}$ of platelet homogenate, $50 \mu \mathrm{l}$ of $0.045 \mathrm{M} \mathrm{KCN}$ and water to yield a final volume of $3 \mathrm{ml}$ during the enzymatic reaction. The cuvettes were covered with parafilm immediately after the addition of $\mathrm{KCN}$ and incubated for $5 \mathrm{~min}$ at $37^{\circ} \mathrm{C}$ in the spectrophotometer. Than NO donors were added and the reaction was initiated by the rapid addition of $60 \mu \mathrm{l}$ DCIP $(0.1 \%(\mathrm{w} / \mathrm{v})$ solution in $0.3 \mathrm{M}$ phosphate buffer) and 100 to $300 \mu \mathrm{l}$ of $0.33 \%$ (w/v) PMS followed by recording the absorbance decrease at $600 \mathrm{~nm}$. Measurements of each sample were performed with four different concentration of PMS. $V_{\max }$ was estimated from a double reciprocal plot of PMS concentration (abscissa) and initial rate of absorbance change at $600 \mathrm{~nm} / \mathrm{min}$ (ordinate). Activity of succinate dehydrogenase was then calculated from the absorbance decrease, using the absorption coefficient for DCIP of $19.1 \mathrm{mM}^{-1} \times \mathrm{cm}^{-1}$ at $600 \mathrm{~nm}$ and was expressed as micromoles of oxidized succinate $\times \min ^{-1}$ per cell number.

Assay of NADH:ubiquinone oxidoreductase activity. The activity of complex I was assayed in the platelet homogenate essentially as described previously (Ragan et al., 1987) using the ubiquinone analogue decylubiquinone (DBQ) as a substrate (Lenaz, 1988).

Preparation of homogenate. Platelet concentrate obtained from 21 of fresh blood was suspended in $50 \mathrm{ml}$ of a medium consisting of $0.160 \mathrm{M} \mathrm{NaCl}, 5 \mathrm{mM}$ EDTA and $10 \mathrm{mM}$ phosphate (K) buffer ( $\mathrm{pH}$ 6.5). The platelets were then washed three times with the suspension medium by centrifugation at $1000 \times \boldsymbol{g}$ for 15 min. The final platelet pellet was suspended in $5 \mathrm{ml}$ of phosphate-buffered saline ( $\mathrm{pH} \mathrm{7.4).}$ 
Thus obtained suspension was cooled and sonically disrupted. Immediately after sonication samples were withdrown for estimation of $\mathrm{NADH}$ : ubiquinone oxidoreductase activity. The $\mathrm{pH}$ of sonicated platelets was controlled and if necessary adjusted to 7.4 with $0.2 \mathrm{M} \mathrm{NaOH}$.

Assay of oxidoreductase activity. Cellular homogenate $(50 \mu \mathrm{l})$ was added to $1 \mathrm{ml}$ of $50 \mathrm{mM}$ Tris/ $\mathrm{HCl}$ buffer, $\mathrm{pH}$ 7.4, containing $100 \mu \mathrm{M} \mathrm{NADH}$ and $2 \mathrm{mM} \mathrm{KCN}$ in a $1 \mathrm{ml}$ cuvette at $37^{\circ} \mathrm{C}$. The incubation mixture was then supplemented with an appropriate amount of freshly prepared NO donors or decomposed donors. The rate of $\mathrm{NADH}$ oxidation was followed at $340 \mathrm{~nm}$ for $3 \mathrm{~min}$ in a UV spectrophotometer (Helios gamma, Unicam) connected to a personal computer. Then $10 \mu \mathrm{l}$ of $16 \mathrm{mM}$ DBQ was added and the stimulated rate of NADH oxidation was taken as the complex I activity, using an absorption coefficient of $6.2 \mathrm{mM}^{-1} \times \mathrm{cm}^{-1}$ at $340 \mathrm{~nm}$. Only the rotenone $(10 \mu \mathrm{M})$ sensitive $\mathrm{NADH}$ oxidation was taken as NADH:ubiquinone oxidoreductase activity. The NO donors were added to the cuvette before the homogenate. The NO donors at the maximal concentrations used in the experiments did not oxidize NADH.

Assay of cytochrome c oxidase activity. The activity of cytochrome $c$ oxidase (ferrocytochrome $c$ :oxygen oxidoreductase, EC 1.9.3.1.) was estimated by a spectrophotometric method based upon the measurement of the rate of oxidation of reduced cytochrome $c$ (Smith, 1955). Cytochrome $c$ was reduced as follows: $100 \mathrm{mg}$ of cytochrome $c$ was dissolved in $10 \mathrm{ml}$ of cold $10 \mathrm{mM}$ phosphate (K) buffer, $\mathrm{pH}$ 7.4. The solution was reduced with $10 \mathrm{mg}$ of potassium ascorbate. The excess of ascorbate was removed by dialysis against 10 $\mathrm{mM}$ phosphate buffer, $\mathrm{pH} 7.4$, for $24 \mathrm{~h}$ with four (3 l) changes of the buffer. Aliquots (0.5 $\mathrm{ml}$ ) of reduced cytochrome $c$ were frozen and kept at $-20^{\circ} \mathrm{C}$ until assay. Cytochrome oxidase activity was measured in a $1 \mathrm{ml}$ cuvette at $37^{\circ} \mathrm{C}$ in a medium consisting of (fi- nal concentration): $45 \mathrm{mM}$ phosphate(K) buffer, $\mathrm{pH}$ 7.4, $50 \mu \mathrm{M}$ reduced cytochrome $c$. The reaction was initiated by the addition of the platelet homogenate. NO donors were added just before the addition of platelet homogenate. Reaction rates were followed by recording the decrease in absorbance at 550 $\mathrm{nm}$. After $3 \mathrm{~min}$ the reaction was terminated by the addition of $10 \mu \mathrm{l}$ of saturated potassium ferricyanide solution to oxidize the remaining reduced cytochrome $c$. The difference between the initial and final absorbance was used to determine the initial substrate concentration. The kinetic of the reaction was similar to that reported by Smith and Conrad (1961), i.e. at the concentration of cytochrome used $(50 \mu \mathrm{M})$ the reaction was first order. All measurements were performed in triplicate. The activity of the enzyme was calculated as $V_{\mathrm{i}}$, by multiplication of the initial substrate concentration by the estimated first-order velocity constant. Results are expressed as micromoles of oxidized cytochrome $c \times \min ^{-1}$ per platelet number and are presented as means \pm S.D.

Data analysis. Data reported in this paper are the mean $( \pm$ S.D.) of the number of determinations indicated (n). Statistical analysis was performed by the Student's $t$-test and elaboration of experimental data by the use of the Slide Write plus (Advanced Graphics Software, Inc, Carlsbad, CA, U.S.A.)

\section{RESULTS}

Figure 1 illustrates the experiments in which the effects of increasing concentrations of NO donors (SNP and SNAP) on the ADPand collagen-induced platelet aggregation were studied. As it is seen in panel A, a two-minute preincubation of platelets with 5-100 $\mu \mathrm{M}$ SNP inhibited, in a dose-dependent manner, the aggregation induced by threshold concentrations of ADP and collagen. The estimated $\mathrm{IC}_{50}$ values were $75 \mu \mathrm{M}$ and $9 \mu \mathrm{M}$, respectively. Total inhibition of the 
ADP- and collagen-evoked aggregation was observed after the treatment of platelet with $299 \mu \mathrm{M}$ and $100 \mu \mathrm{M}$ SNP, respectively.

Panel B shows the results of similar experiments with SNAP as the NO donor. SNAP inhibited, in a dose-dependent manner, the ADP- and collagen-induced platelet aggregation at the concentration range of 5 to $50 \mu \mathrm{M}$
PRP samples using a lumiaggregometer. Aggregation and secretion of ATP from platelet dense granules were recorded simultaneously. The blocking of mitochondrial energy production by antimycin A near completely reduced the collagen-induced dense granule secretion and only slightly affected platelet aggregation.
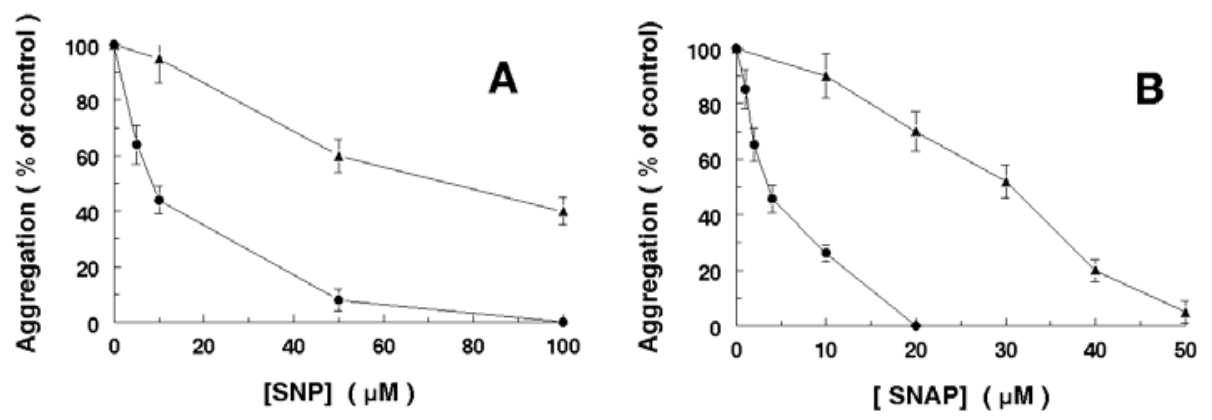

Figure 1. The effect of SNP (panel A) and SNAP (panel B) on collagen- and ADP-induced platelet aggregation.

PRP (0.6 ml) was incubated at $37^{\circ} \mathrm{C}$ without (control) or with SNP or SNAP added to the final concentration as indicated. Aggregation was initiated by the addition of threshold concentrations of ADP $(8-13 \mu \mathrm{M})(\mathbf{\Delta})$ or collagen $(10-15 \mu \mathrm{g} / \mathrm{ml})(\mathbf{O})$. The extent of platelet aggregation was measured $3 \mathrm{~min}$ after the addition of the agonist, and the maximum extent of aggregation was taken as $100 \%$. Decomposed SNP and SNAP added to the final concentration of $300 \mu \mathrm{M}$ and $100 \mu \mathrm{M}$, respectively, exerted no observable effect on ADP- and collagen-induced platelet aggregation.

with $\mathrm{IC}_{50}$ values of 30 and $5 \mu \mathrm{M}$, respectively. Total inhibition of the ADP- and collagen-evoked aggregation was observed after the incubation of platelets with $50 \mu \mathrm{M}$ and 20 $\mu \mathrm{M}$ SNAP, respectively.

As seen in Fig. 2, SNAP and SNP at concentrations of 10 to $200 \mu \mathrm{M}$ reduced the thrombin- (panel A) and collagen-induced (panel B) serotonin release. The inhibition of secretion was concentration-dependent. Fiftypercent inhibition of the secretion was observed in the presence of $50 \mu \mathrm{M}$ SNAP or $100 \mu \mathrm{M}$ SNP.

Figure 3 shows the results of experiments which were performed to determine how the blocking of electron transport in the respiratory chain by antimycin A affects the collagen-induced platelet aggregation and secretion. Platelet responses were measured in
The results presented in Table 1 show that the rate of glycolysis in intact platelets was increased by respiratory chain blockers (cyanide, antimycin A), uncouplers (2,4-dinitrophenol), platelet activator (collagen) and by SNP (10 to $200 \mu \mathrm{M}$ ) and SNAP (10 to 100 $\mu \mathrm{M})$. Decomposed SNP $(200 \mu \mathrm{M})$ or SNAP $(100 \mu \mathrm{M})$ did not affect glycolysis in intact platelets. The stimulatory effect of SNP $(100 \mu \mathrm{M})$ and SNAP was similar to that observed after the blocking of the respiratory chain by antimycin A or cyanide and to that produced by aggregating concentrations of collagen. The rise in the rate of glycolysis produced by SNP $(200 \mu \mathrm{M})$ or SNAP $(100 \mu \mathrm{M})$ was not reduced by ODQ $(10 \mu \mathrm{M})$, a specific inhibitor of NO-sensitive soluble guanylate cyclase. This ODQ concentration was able to reduce near completely the inhibitory effect 
of SNP $(200 \mu \mathrm{M})$ on the collagen-induced aggregation of porcine platelets in PRP (not shown).

To establish how NO donors affect glycolysis in a cell-free system, i.e. in a system containing all the glycolytic enzymes and depleted of intact mitochondria, we measured the effect of NO donors on lactate production in platelet
(0.1-0.6 $\mathrm{mM}$ ) do not affect the glycolysis rate measured in the cell-free system.

Table 3 shows that respiratory chain blockers (cyanide and antimycin A), SNP (50-200 $\mu \mathrm{M})$ and SNAP $(20-100 \mu \mathrm{M})$ inhibited the oxygen consumption by platelets. The effect exerted by the NO donors was dose-dependent. The degree of this inhibition was

Table 1. Glycolytic activity of intact platelets in the presence of collagen, nitric oxide donors, uncoupler of oxidative phosphorylation, respiratory chain blockers and guanylate cyclase inhibitor

\begin{tabular}{|c|c|c|c|}
\hline Experiment & Additions & & $\begin{array}{l}\text { Lactate production } \\
\mu \text { moles } / \text { min per } 10^{11} \text { cells }\end{array}$ \\
\hline \multirow{5}{*}{$\mathrm{A}$} & Control & & $3.0 \pm 0.1$ \\
\hline & Collagen & $20 \mu \mathrm{g} / \mathrm{ml}$ & $5.3 \pm 0.3^{* * *}$ \\
\hline & Cyanide & $1 \mathrm{mM}$ & $5.2 \pm 0.3^{* * *}$ \\
\hline & Antimycin A & $10 \mu \mathrm{g} / \mathrm{ml}$ & $4.9 \pm 0.2^{* * *}$ \\
\hline & 2,4-Dinitrophenol & $1 \mathrm{mM}$ & $5.7 \pm 0.4^{* * *}$ \\
\hline \multirow{7}{*}{ B } & \multicolumn{2}{|l|}{ Control } & $3.2 \pm 0.1$ \\
\hline & SNP & $10 \mu \mathrm{M}$ & $3.7 \pm 0.1^{*}$ \\
\hline & SNP & $50 \mu \mathrm{M}$ & $4.6 \pm 0.2^{* *}$ \\
\hline & SNP & $100 \mu \mathrm{M}$ & $5.5 \pm 0.4^{* * *}$ \\
\hline & SNP & $200 \mu \mathrm{M}$ & $5.6 \pm 0.4^{* * *}$ \\
\hline & SNP $200 \mu \mathrm{M}+$ ODQ & $10 \mu \mathrm{M}$ & $5.5 \pm 0.4^{* * *}$ \\
\hline & Decomposed SNP & $200 \mu \mathrm{M}$ & $3.4 \pm 0.4$ \\
\hline \multirow[t]{7}{*}{$\mathrm{C}$} & \multicolumn{2}{|l|}{ Control } & $3.3 \pm 0.3$ \\
\hline & SNAP & $10 \mu \mathrm{M}$ & $3.4 \pm 0.3$ \\
\hline & SNAP & $20 \mu \mathrm{M}$ & $4.2 \pm 0.4^{* * *}$ \\
\hline & SNAP & $50 \mu \mathrm{M}$ & $4.7 \pm 0.5^{* * *}$ \\
\hline & SNAP & $100 \mu \mathrm{M}$ & $5.7 \pm 0.5^{* * *}$ \\
\hline & SNAP $100 \mu \mathrm{M}+$ ODQ & $10 \mu \mathrm{M}$ & $5.5 \pm 0.5^{* * *}$ \\
\hline & Decomposed SNAP & $200 \mu \mathrm{M}$ & $3.4 \pm 0.3$ \\
\hline
\end{tabular}

Platelets $\left(2 \times 10^{9}\right.$ cells $\left./ \mathrm{ml}\right)$ suspended in dialyzed plasma were incubated at $37^{\circ} \mathrm{C}$ for $30 \mathrm{~min}$ without (control) and with various substances added to the final concentrations as indicated. Further details in Materials and Methods. The numbers are means \pm S.D. ( $(n=4)$ of one representative (out of six ) experiment performed on single platelet preparation. Lactate production in the control varied from 2.7 to $3.8 \mu$ moles $\times \min ^{-1} \times 10^{-11}$ cells. ${ }^{*} P<0.05,{ }^{* *} P<0.01,{ }^{* * *} P<0.001$.

homogenate. Platelet homogenate was used instead of a high speed supernatant fraction (cytosol) since, as established by Akkerman (1978), 97\% of the total hexokinase activity in platelets is membrane bound. As it is seen from Table 2, respiratory chain blockers (cyanide, antimycin A), uncouplers (2,4-dinitrophenol) SNAP $(20-100 \mu \mathrm{M})$ and SNP similar to that observed in the presence of cyanide and antimycin A. Neither decomposed SNP $(200 \mu \mathrm{M})$ nor SNAP $(100 \mu \mathrm{M})$ affected the oxygen consumption by intact platelets. The inhibition of oxygen consumption by intact platelets produced by SNP $(200 \mu \mathrm{M})$ or SNAP $(100 \mu \mathrm{M})$ was not abolished by ODQ (10 $\mu \mathrm{M})$. 

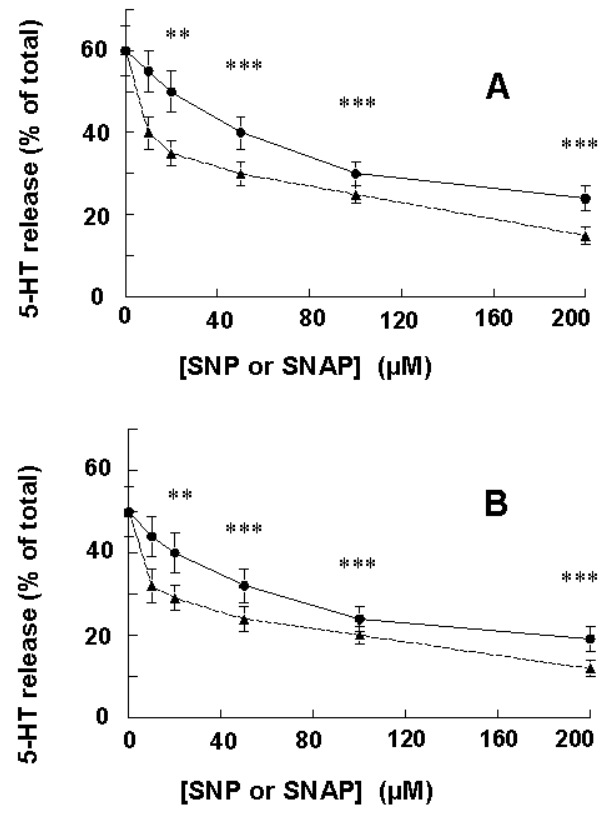

Figure 2. The effect of NO donors on thrombin(A) and collagen-induced (B) serotonin release.

Aliquots of $\left[{ }^{3} \mathrm{H}\right] 5$-HT-loaded platelets were incubated without (control) or with $\operatorname{SNP}(\boldsymbol{O})$ or $\operatorname{SNAP}(\boldsymbol{\Delta})$ added to the final concentration as indicated. Secretion was initiated by the addition of thrombin (panel A) or collagen (panel B) to the final concentration of $0.3 \mathrm{U} / \mathrm{ml}$ and $20 \mu \mathrm{g} / \mathrm{ml}$, respectively. The amount of $\left[{ }^{3} \mathrm{H}\right]$ serotonin released within 3 min after an addition of the stimulus was estimated. Decomposed SNP and SNAP added to the final concentration of $300 \mu \mathrm{M}$ and 100 $\mu \mathrm{M}$, respectively, did not affect the serotonin secretion. Results are expressed as percentage of the total amount of $\left[{ }^{3} \mathrm{H}\right]$ serotonin contained in unstimulated platelets and are presented as means \pm S.D. All experiments were performed at least in quadruplicate using five different platelet preparations. The differences between the control and NO donors-treated platelets are significant $\left({ }^{* *} P<0.05,{ }^{* * *} P<0.01\right)$.

Table 4 demonstrates the results of experiments in which the effect of NO donors on the activity of cytochrome oxidase and succinate dehydrogenase in platelet homogenate was studied. Both SNP (10 to $200 \mu \mathrm{M}$ ) and SNAP (10 to $200 \mu \mathrm{M}$ ) reduced, in a concentration-dependent fashion, the activity of cytochrome oxidase. The estimated $\mathrm{IC}_{50}$ values were 60 $\mu \mathrm{M}$ and $9 \mu \mathrm{M}$, respectively. Nearly total inhibition of cytochrome oxidase was observed in the presence of $100 \mu \mathrm{M}$ SNAP or $300 \mu \mathrm{M}$ SNP. Neither of the NO donors used at con-
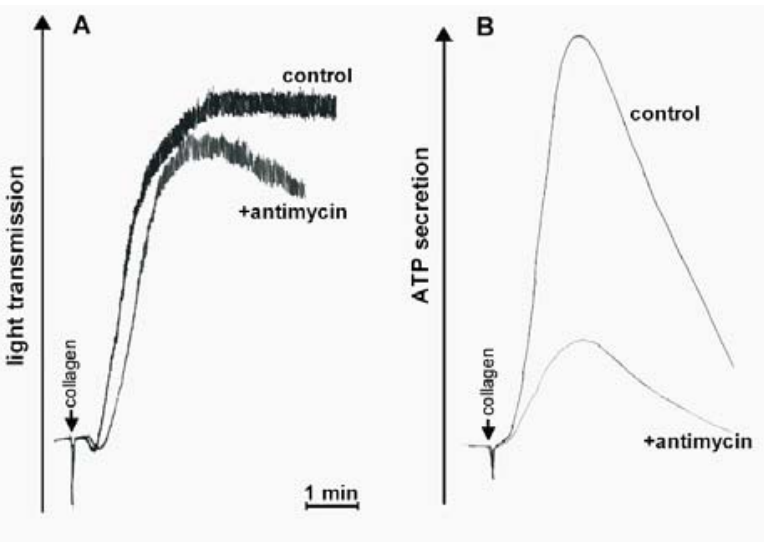

Figure 3. The effect of antimycin on collagen-induced platelet aggregation and secretion.

PRP was incubated without (control) or with antimycin A added to the final concentration of $10 \mu \mathrm{g} / \mathrm{ml}$. Aggregation (panel A) and secretion (panel B) were initiated by the addition of supra-threshold concentrations of collagen (20 $\mu \mathrm{g} / \mathrm{ml})$. Optical aggregation (panel A) and platelet release reaction (panel B) were monitored simultaneously as described in Methods. The results of one representative experiment (out of five) are presented.

centrations up to $100 \mu \mathrm{M}$ (SNAP) or $300 \mu \mathrm{M}$ (SNP) affected the activities of NADH: ubiquinone oxidoreductase and succinate dehydrogenase.

\section{DISCUSSION}

Platelets are fairly active metabolically and have a total ATP turnover rate of about 3-8 times that of resting mammalian muscle (Akkerman, 1978; Akkerman et al., 1978; Holmsen, 1981; Niu et al., 1996). Platelets contain mitochondria which enable these cells to produce energy both in the oxidative and anaerobic way (Holmsen, 1981). Under aerobic conditions, ATP is produced by aerobic glycolysis using glucose or glycogen which can account for $30-50 \%$ of total ATP production, and by oxidative metabolism using glu- 
cose and glycogen $(6-11 \%)$, amino-acids $(7 \%)$ or free fatty acids (20-40\%) (Holmsen 1981; Guppy et al., 1990; Niu et al., 1996). The inhibition of mitochondrial respiration by removing oxygen or by respiratory chain blockers (antimycin A, cyanide, rotenone) results in the stimulation of glycolytic flux (Guppy et $a l ., 1990)$. This phenomenon is known as Pasteur effect and indicates that in platelets energy production in platelets may decrease their responses.

It is well established that platelet responses have different metabolic energy (ATP) requirements increasing in the order: aggregation < dense and alfa granule secretion < acid hydrolase secretion (Holmsen et al., 1982; Verhoeven et al., 1984; Morimoto \& Ogihara, 1996).

Table 2. Glycolytic activity of platelet homogenate in the presence of respiratory chain inhibitors and NO donors

\begin{tabular}{lcc}
\hline Additions & \multicolumn{2}{c}{$\begin{array}{c}\text { Lactate production } \\
\mu \text { moles } / \text { min } \text { per } 10^{11} \text { cells equivalent }\end{array}$} \\
\hline None & $1 \mathrm{mM}$ & $3.0 \pm 0.3$ \\
Cyanide & $10 \mu \mathrm{g} / \mathrm{ml}$ & $3.1 \pm 0.3$ \\
Antimycin A & $1 \mathrm{mM}$ & $2.7 \pm 0.3$ \\
2,4 -Dinitrophenol & & $2.8 \pm 0.3$ \\
& $0.1 \mathrm{mM}$ & $3.2 \pm 0.3$ \\
SNP & $0.5 \mathrm{mM}$ & $3.1 \pm 0.3$ \\
SNP & $0.6 \mathrm{mM}$ & $2.8 \pm 0.3$ \\
SNP & $10 \mu \mathrm{M}$ & $3.0 \pm 0.4$ \\
& $20 \mu \mathrm{M}$ & $3.2 \pm 0.3$ \\
SNAP & $50 \mu \mathrm{M}$ & $2.7 \pm 0.3$ \\
SNAP & $100 \mu \mathrm{M}$ & $3.3 \pm 0.3$ \\
SNAP & & \\
SNAP & & \\
\hline
\end{tabular}

Platelet homogenate (equivalent of $2 \times 10^{9}$ cells $/ \mathrm{ml}$ ) was incubated at $37^{\circ} \mathrm{C}$ for 30 min without (control) and with various substances added to the final concentrations as indicated. Further details in Materials and Methods. The numbers are means \pm S.D. $(n=4)$ of one representative (out of six) experiment performed on single platelet preparation.

glycolysis and mitochondrial respiration are tightly functionally connected (Akkerman, 1978; Holmsen, 1981; Guppy et al., 1995; Niu et al., 1996).

It has been reported that the activation of human platelets by high concentration of thrombin is accompanied by an acceleration of lactate production and an increase in oxygen consumption (Akkerman \& Holmsen, 1981; Niu et al., 1996). The results presented here suggest that also porcine blood platelets stimulated by collagen produce more lactate. This indicates that both glycolytic and oxidative ATP production supports platelet responses. This also indicates that blocking of
Much less is known about the contribution of the mitochondrial energy production in the process of platelet secretion and aggregation. Studies performed on washed human platelets have shown that oxidative energy production is essential for full (maximal aggregation) platelet response, and that anaerobic glycolysis failed to fully compensate for impaired (by anoxia) oxidative phosphorylation (Akahori et al., 1995). They also showed that in platelets incubated under hypoxic conditions cellular ATP and ADP levels were preserved but this was associated with a rise in AMP concentration and a decrease in adenylate energy charge. 
To establish the requirements of porcine platelet responses (aggregation and secretion) for mitochondrial energy production we measured the effect of antimycin A on the collagen-induced aggregation and secretion using a lumiaggregometer. Such approach enabled us to measure simultaneously aggregation and secretion and to establish their dependence on the oxidative energy production. It was found that the diminished energy supply from mitochondria in antimycin A-treated cells was compensated by a rise in energy sup- platelet secretion. In conclusion the results indicate that in porcine blood platelets mitochondrial energy production is critical for dense granule secretion but not for the aggregation process.

Studies performed on cells other than platelets indicate that the rate of mitochondrial energy production may by controlled by NO (Brown, 1999; 2001). According to Brown (1999) nanomolar concentrations of NO, i.e. concentrations that were reported to be able to inhibit cytochrome oxidase and mitochon-

Table 3. Oxygen consumption by intact platelets in the presence of nitric oxide donors and respiratory chain inhibitors

\begin{tabular}{|c|c|c|c|}
\hline Experiment & Additions & & $\begin{array}{l}\text { Oxygen consumption } \\
\text { nanomoles } \mathrm{O}_{2} / \mathrm{min} \\
\text { per } 10^{11} \text { cells }\end{array}$ \\
\hline $\mathrm{A}$ & $\begin{array}{l}\text { None } \\
\text { Cyanide } \\
\text { Antimycin A }\end{array}$ & $\begin{array}{c}1 \mathrm{mM} \\
0 \mu \mathrm{g} / \mathrm{ml}\end{array}$ & $\begin{aligned} 400 & \pm 50 \\
40 & \pm 10^{* * *} \\
60 & \pm 11^{* * *}\end{aligned}$ \\
\hline B & $\begin{array}{l}\text { None } \\
\text { SNP } \\
\text { SNP } \\
\text { SNP } \\
\text { SNP } \\
\text { SNP } 200 \mu \mathrm{M}+\text { ODQ } \\
\text { Decomposed SNP }\end{array}$ & $\begin{array}{c}10 \mu \mathrm{M} \\
50 \mu \mathrm{M} \\
150 \mu \mathrm{M} \\
200 \mu \mathrm{M} \\
10 \mu \mathrm{M} \\
200 \mu \mathrm{M}\end{array}$ & $\begin{aligned} 410 & \pm 50 \\
390 & \pm 50 \\
350 & \pm 40^{*} \\
250 & \pm 30^{* * *} \\
50 & \pm 11^{* * *} \\
60 & \pm 11^{* * *} \\
380 & \pm 50\end{aligned}$ \\
\hline $\mathrm{C}$ & $\begin{array}{l}\text { None } \\
\text { SNAP } \\
\text { SNAP } \\
\text { SNAP } \\
\text { SNAP } \\
\text { SNAP } 100 \mu \mathrm{M}+\text { ODQ } \\
\text { Decomposed SNP }\end{array}$ & $\begin{array}{c}10 \mu \mathrm{M} \\
20 \mu \mathrm{M} \\
50 \mu \mathrm{M} \\
100 \mu \mathrm{M} \\
10 \mu \mathrm{M} \\
100 \mu \mathrm{M}\end{array}$ & $\begin{aligned} 390 & \pm 50 \\
380 & \pm 50 \\
360 & \pm 40^{*} \\
250 & \pm 35^{* * *} \\
40 & \pm 12^{* * *} \\
50 & \pm 11^{* * *} \\
380 & \pm 50\end{aligned}$ \\
\hline
\end{tabular}

Oxygen consumption was measured in platelet concentrates in dialyzed plasma $\left(1.5 \times 10^{9}\right.$ platelets $\left./ \mathrm{ml}\right)$ at $\mathrm{pH} 7.4$. The changes in oxygen concentration in a closed vessel were measured using a Clark oxygen electrode at $37^{\circ} \mathrm{C}$. Further details in Materials and Methods. The results of one representative experiment (out of five) are presented. Total oxygen consumption in the control varied from 240 to $410 \mathrm{nmol} / \mathrm{min}$ per $10{ }^{11}$ cells $.{ }^{*} P<0.05,{ }^{* * *} P<0.001$.

ply from glycolysis which was manifested by enhanced lactate formation. Such compensation allowed the cells to produce an amount of energy which was sufficient for their aggregation. However, the enhanced glycolytic ATP production was not able to satisfy the dramatic rise in energy demand associated with drial energy production are expected to be present in capillary blood stream even at basal conditions. In tissues where inflammation occurs a variety of cells can be induced to express the inducible form of NO synthase, leading to the production of such concentrations of NO which are able to inhibit cellular 
respiration (Brown, 1999; Oddis \& Finke, 1995; Geng et al., 1992).

Although the basal levels of free NO are normally quite low (nanomolar), local NO concentrations have been shown to increase to 4 to $30 \mu \mathrm{M}$ under pathologic conditions (Hooper et al., 1955; Malinski et al., 1993). Thus, in vivo platelets are likely to be exposed even to micromolar concentrations of NO.

The present results indicate that exogenously added NO (in the form of NO donors) stimulates glycolysis in intact porcine platelets. The degree of this stimulation was similar to that observed after the blocking of parently not present. Since in platelets glycolysis and mitochondrial respiration are tightly functionally connected, this can be interpreted to mean that the stimulatory effect of NO on glycolysis in intact platelets may be produced by non-functional mitochondria. This can be really the case since NO donors are able to inhibit both mitochondrial respiration and platelet cytochrome oxidase. Interestingly, the concentrations of NO donors inhibiting mitochondrial respiration and cytochrome oxidase were similar to those stimulating glycolysis in intact platelets. In conclusion, nitric oxide is able to reduce

Table 4. The effect of NO donors on the activity of NADH: ubiquinone oxidoreductase, succinate dehydrogenase and cytochrome oxidase

\begin{tabular}{|c|c|c|c|c|}
\hline Experiment & Additions & $\begin{array}{l}\text { NADH: ubiquinone } \\
\text { oxidoreductase } \\
\mu \text { moles } / \text { min } \\
\text { per } 10^{12} \text { cells }\end{array}$ & $\begin{array}{l}\text { Succinate } \\
\text { dehydrogenase } \\
\mu \text { moles } / \mathrm{min} \\
\text { per } 10^{12} \text { cells }\end{array}$ & $\begin{array}{l}\text { Cytochrome oxidase } \\
\mu \text { moles } / \mathrm{min} \\
\text { per } 10^{12} \text { cells }\end{array}$ \\
\hline \multirow{8}{*}{$\mathrm{A}$} & None & $18.3 \pm 1.9$ & $0.96 \pm 0.06$ & $3.2 \pm 0.4$ \\
\hline & SNAP $\quad 5 \quad \mu \mathrm{M}$ & $17.9 \pm 1.8$ & $0.96 \pm 0.06$ & $3.1 \pm 0.4$ \\
\hline & SNAP $\quad 10 \mu \mathrm{M}$ & $18.0 \pm 1.9$ & $0.94 \pm 0.04$ & $3.0 \pm 0.3$ \\
\hline & SNAP $\quad 20 \mu \mathrm{M}$ & $18.1 \pm 1.7$ & $0.93 \pm 0.04$ & $2.8 \pm 0.4^{*}$ \\
\hline & SNAP $\quad 50 \mu \mathrm{M}$ & $18.2 \pm 1.9$ & $0.92 \pm 0.05$ & $2.4 \pm 0.2^{* *}$ \\
\hline & SNAP $100 \mu \mathrm{M}$ & $18.4 \pm 2.0$ & $0.90 \pm 0.04$ & $0.4 \pm 0.1^{* * *}$ \\
\hline & Decomposed & & & \\
\hline & SNAP $100 \mu \mathrm{M}$ & $17.9 \pm 1.9$ & $0.90 \pm 0.04$ & $3.1 \pm 0.4$ \\
\hline & None & $18.0 \pm 1.8$ & $0.98 \pm 0.07$ & $3.6 \pm 0.3$ \\
\hline & SNP $10 \mu \mathrm{M}$ & $17.9 \pm 1.8$ & $0.98 \pm 0.07$ & $3.3 \pm 0.4_{*}$ \\
\hline & $\mathrm{SNP} \quad 50 \mu \mathrm{M}$ & $18.1 \pm 1.9$ & $0.96 \pm 0.06$ & $3.1 \pm 0.3^{*}$ \\
\hline & $\mathrm{SNP} \quad 100 \mu \mathrm{M}$ & $18.2 \pm 1.9$ & $0.96 \pm 0.06$ & $2.8 \pm 0.2^{* *}$ \\
\hline & $\mathrm{SNP} \quad 150 \mu \mathrm{M}$ & $18.4 \pm 2.0$ & $0.94 \pm 0.05$ & $2.3 \pm 0.1_{* * * *}^{* * *}$ \\
\hline B & SNP $200 \mu \mathrm{M}$ & $18.3 \pm 1.8$ & $0.95 \pm 0.05$ & $1.6 \pm 0.1_{* * * *}^{* * *}$ \\
\hline & $\mathrm{SNP} \quad 300 \mu \mathrm{M}$ & $17.8 \pm 1.8$ & $0.94 \pm 0.05$ & $0.5 \pm 0.1^{\text {*.* }}$ \\
\hline & Decomposed & & & \\
\hline & $\mathrm{SNP} \quad 300 \mu \mathrm{M}$ & $18.0 \pm 1.9$ & $0.94 \pm 0.05$ & $3.3 \pm 0.4$ \\
\hline
\end{tabular}

Activities were measured as described in Materials and Methods. Results are expressed as micromoles of oxidized substrate (NADH, succinate, cytochrome $c) /$ min per $10^{12}$ cells. Mean values \pm S.D. $(\mathrm{n}=16)$ are reported. ${ }^{*} P<0.05,{ }^{* *} P<0.01$, ${ }^{* * *} P<0.001$.

platelet mitochondrial energy production by an uncoupler (DNP) or respiratory chain inhibitors (antimycin A or cyanide). At the same time NO donors, DNP, antimycin A and cyanide had no effect on the rate of glycolysis in a cell-free system (homogenate) in which functional (coupled) mitochondria were ap- platelet mitochondrial energy production through the inhibition of cytochrome oxidase activity.

Although in our experimental system (platelet homogenate) NO donors are able directly to affect cytochrome oxidase, their effect may differ in intact cell where they are 
known to stimulate soluble guanylate cyclase. Thus produced cGMP at least potentially can affect cellular respiration. Such a scenario is, however, excluded, since the effect of the NO donors on platelet respiration and glycolysis was not reduced after the blocking of NO-sensitive soluble guanylate cyclase by ODQ. This is in agreement with previous results showing that the inhibitory effect of NO on the oxygen consumption by rat aortic cells is not abolished after the blocking of soluble guanylate cyclase by ODQ (Borutaite et al., 2001).

Nitric oxide donors were not able to inhibit succinate dehydrogenase in platelet mitochondria. This is surprising since the succinate:cytochrome $c$ reductase isolated from beef heart mitochondria was reported to be strongly inhibited after nitric oxide treatment. A plausible explanation is that in the experimental system we used (platelet homogenate) succinate dehydrogenase might be protected from nitric oxide when complexed with (unknown) protein inducing conformational changes blocking the access of NO to the iron center. This is based on the observations of Welter et al. (1996) that ubiquinol:cytochrome reductase (component of reductase cytochrome $c$ complex) may be protected from NO when complexed with succinate:ubiquinone reductase (another component of reductase cytochrome $c$ complex).

Our results show that also platelet $\mathrm{NADH}$ :ubiquinone oxidoreductase is not affected by NO donors. However, it should be stressed that in the experimental system we used, broken platelets were exposed to the NO donors for a short time (minutes). Studies performed on intact J774 cells have shown that mitochondrial complex I is inhibited only after a prolonged (6-18 h) exposure to NO and that this inhibition appears to result from S-nitrosylation of critical thiols in the enzyme complex (Clementi et al., 1998). Further studies are needed to establish whether long term exposure of platelets to NO affects mitochondrial complexes I and II.
Does the NO-mediated blocking of mitochondrial energy production explain the inhibitory effect of nitric oxide on platelet responses? Comparison of the concentrations of SNP and SNAP affecting cytochrome oxidase activity and mitochondrial respiration with those reducing the platelet responses indicates that NO cannot significantly reduce platelet aggregation through the inhibition of oxidative energy production. By contrast, the concentrations of the NO donors inhibiting platelet secretion, mitochondrial respiration and cytochrome oxidase were similar. This and the fact that the platelet release reaction strongly depends on the oxidative energy production may suggest that in porcine platelets NO can affect platelet secretion through the inhibition of mitochondrial energy production at the step of cytochrome oxidase.

Taking into account that platelets may contain NO synthase and are able to produce significant amounts of NO (Berkels et al., 1997) it seems possible that nitric oxide can function in these cells as a physiological regulator of mitochondrial energy production.

\section{R E F E R E N C E S}

Akahori M, Uedono Y, Yamagami K, Takeyama N, Kitazawa Y. (1995) Hypoxia alters the energy metabolism and aggregation of washed human platelets. Haematologia.; 26: 191-8.

Akkerman JWN. (1978) Regulation of carbohydrate metabolism in platelets. Thromb Haemost.; 39: 712-24.

Akkerman JWN, Holmsen H. (1981) Interrelationships among platelet responses: studies on the burst in proton liberation, lactate production, and oxygen uptake during platelet aggregation and $\mathrm{Ca}^{2+}$ secretion. Blood.; 57: 956-65.

Akkerman JWN, Gorter G, Sixma JJ. (1978) Regulation of glycolytic flux in human platelets. Biochim Biophys Acta.; 541: 241-50.

Beghetti M, Sparling C, Stephens D. (2003) Inhaled NO inhibits platelet aggregation and 
elevates plasma but not intraplatelet cGMP in healthy human volunteers. Am J Physiol Heart Circ Physiol.; 285: H637-42.

Berkels R, Bertsch A, Zuther T, Dhein S, Stockklauser K, Rosen P, Rosen R. (1997) Evidence for a NO synhase in porcine platelets which is stimulated during activation/aggregation. Eur J Haematol.; 58: 307-13.

Born GVR. (1963) Quantitative investigation into aggregation of blood platelets. $J$ Physiol.; 168: 78-95.

Borutaite V, Matthias A, Harris H, Moncada S, Brown GC. (2001) Reversible inhibition of cellular respiration by nitric oxide in vascular inflammation. Am J Physiol Heart Circ Physiol.; 281: H2256-60.

Brown GC. (1999) Nitric oxide and mitochondrial respiration. Biochim Biophys Acta; 1411: $351-69$.

Brown GC. (2001) Regulation of mitochondrial respiration by nitric oxide inhibition of cytochrome $c$ oxidase. Biochim Biophys Acta.; 1504: $46-57$.

Chrono-Log Diagnostic Protocol. (1987) Manual for testing with the whole-blood aggregometer model 550. Chrono-Log Corp. Havertown, PA, USA.

Clementi E. Brown GC, Feelishc, and Moncada S. (1998) Persistent inhibition of cell respiration by nitric oxide: Crucial role of S-nitrosylation of mitochondrial complex I and protective action of glutathione. Med Sci.; 95: 7631-6.

Geng Y, Hansson GK, Holme E. (1992) Interferon-gamma and tumor necrosis factor synergize to induce nitric oxide production and inhibit mitochondrial respiration in vascular smooth muscle cells. Circul Res.; 71: 1268- 76 .

Gordge MP, Hothersall JS, Noronha-Dutra AA. (1998) Evidence for a cyclic GMP-independent mechanism in the anti-platelet action of $S$-nitrosoglutathione. Br J Pharmacol.; 124: 141-8.

Guppy M, Whisson ME, Sabaratnam R, Withers P, Brand K. (1990) Alternative fuels for platelet storage: a metabolic study. Vox Sang.; 59: 146-52.

Guppy M, Abas L, Arthur PG, Whisson ME. (1995) The Pasteur effect in human platelets: implications for storage and metabolic control. Br J Haematol.; 91: 752-7.

Gutmann I, Wahlefeld AW. (1985) L-(+)Lactate determination with lactate dehydrogenase and NAD. In Methods of Enzymatic Analysis. Bergmeyer HU, ed, pp 1464-8. VCH Velagsgesellschaft mbH. Weiheim.

Holmsen H. (1981) Biochemistry of the platelet: energy metabolism. in Haemostasis and Thrombosis: Basic Principles and Clinical Practice. Colman RW, Hirsh J, Marder VJ, Salzman EW, eds, pp 431-43, JB Lippincott Comp. Philadelphia.

Holmsen H, Dangelmaier CA. (1989) Measurement of secretion of serotonin. Methods Enzymol.; 169: 195-205.

Holmsen H, Kaplan KL, Dangelmaier CA. (1982) Differential energy requirements for platelet responses. Biochem J.; 208: 9-18.

Hooper DC, Ohnishi ST, Kean R, Numagami Y, Dietzschold B, Koprowski H. (1995) Local nitric oxide production in viral and autoimmune diseases of the central nervous system. Proc Natl Acad Sci USA.; 92: 5312-6.

King TE. (1967) Preparation of succinate dehydrogenase and reconstitution of succinate oxidase. Methods Enzymol.; 10: $322-31$.

Lantoine F, Brunet A, Bedioui F, Devynck J, Devynck MA. (1995) Direct measurement of nitric oxide production in platelets: relationship with cytosolic $\mathrm{Ca}^{2+}$ concentration. Biochem Biophys Res Commun.; 215: 842-8.

Lenaz G. (1988) Quinone specificity of complex I. Biochim Biophys Acta.; 1364: 207-21

Malinski T, Bailey F, Zhang ZG, Chopp M. (1993) Nitric oxide measured by a porphyrinic microsensor in rat brain after transient middle cerebral artery occlusion. J Cereb Blood Flow Metab.; 13: 355-8. 
Moncada S, Palmer RMJ, Higgs EA. (1991) Nitric oxide: physiology, pathophysiology and pharmacology. Pharmacol Rev.; 2: 109-42.

Morimoto T, Ogihara S. (1996) ATP is required in platelet serotonin exocytosis for protein phosphorylation and priming of secretory vesicles docked on the plasma membrane. J Cell Sci.; 109: 113-8.

Nishimura I, Minakami S. (1975) Effect of hydrogen ions concentration on energy metabolism in pig platelets Biochim Biophys Acta; 396: $1-10$.

Niu X, Arthur P, Abas L, Whisson M, Guppy M. (1996) Carbohydrate metabolism in human platelets in a low glucose medium under aerobic conditions. Biochim Biophys Acta.; 1291: 97-106.

Oddis CV, Finke MS. (1995) Cytokine-stimulated nitric oxide production inhibits mitochondrial activity in cardiac myocytes. Biochem Biophys Res Commun.; 213: 1002-9.

Radomski MW, Zakar T, Salas E. (1996) Nitric oxide in platelets. Methods Enzymol.; 269: 88-107.

Ragan CI, Wilson MT, Derley-Usmar VM, Lowe PN. (1987) Mitochondria: a Practical Approach. Darley-Usmar VM, Rickewood D, Wilson MT. eds, pp 79-112. IRL Press Oxford.

Riddell DR, Owen JS. (1999) Nitric oxide and platelet aggregation. Vitam Horm.; 57: $25-48$.

Schmidt HH, Lohmann SM, Walter U. (1993) The nitric oxide and cGMP signal transduction system: regulation and mechanism of action. Biochim Biophys Acta.; 1178: 153-75.

Singh RJ, Hogg N, Kalyanaraman B. (1996) Mechanism of nitric oxide release from S-nitrosothiols. J Biol Chem.; 271: 18596-603.

Smith L. (1955) Cytochrome $c$ oxidase. In Methods of Biochemical Analysis, vol. 2, pp 427-9. Glick D. Wiley (Interscience), New York.
Smith L, Conrad H. (1961) A study of the kinetics of the oxidation of cytochrome $c$ by cytochrome oxidase. Arch Biochem Biophys.; 63: $403-13$.

Sogo N, Magid KS, Shaw CA, Weeb DJ, Megson IL. (2000) Inhibition of human platelet aggregation by nitric oxide donors drugs: relative contribution of cGMP-independent mechanisms. Biochem Biophys Res Commun.; 279: 412-19.

Stone JR, Marletta MA. (1996) Spectral and kinetic studies on the activation of soluble guanylate cyclase by nitric oxide. Biochemistry.; 35: 1093-9.

Szabó C. (1996) Physiological and pathophysiological roles of nitric oxide in the central nervous system. Brain Res Bulletin.; 41: 3141.

Titheradge MA. (1999) Nitric oxide in septic shock. Biochim Biophys Acta.; 1411: 434-55.

Verhoeven AJM, Mommersteeg ME, Akkerman JWN. (1984) Metabolic energy is required in human platelets at any stage during optical aggregation and secretion. Biochim Biophys Acta.; 800: 242-50.

Waldmann R, Walter U. (1989) Cyclic nucleotide elevating vasodilators inhibit platelet aggregation at an early step of the activation cascade. Eur J Pharmacol.; 159: 317-20.

Wang GR, Zhu Y, Halushka PV, Lincoln TM, Mendelsohn ME. (1998) Mechanism of platelet inhibition by nitric oxide: in vivo phosphorylation of thromboxane receptor by cyclic GMP-dependent protein kinase. Proc Natl Acad Sci USA.; 95: 4888-93.

Welter R, Yu L, Yu CA. (1996) The effect of nitric oxide on electron transport complexes. Arch Biochem Biophys.; 331: 9-14.

Yamamoto T, Bing RJ. (2000), Nitric oxide donors. Proc Soc Exp Biol Med.; 225: 200-6.

Zhou Q, Hellermann GR, Solomonson LP. (1995) Nitric oxide release from resting human platelets. Thromb Res.; 77: 87-96. 